\title{
Role of diagnostic hysteroscopy in evaluation of abnormal uterine bleeding and its histopathological correlation
}

\author{
Kamlesh R. Chaudhari*, Parul Sathe
}

Department of Obstetrics \& Gynecology, K.J. Somaiya Medical College and Research Centre, Mumbai, MH, India

Received: 17 July 2014

Accepted: 8 August 2014

\section{*Correspondence:}

Dr. Kamlesh R. Chaudhari,

E-mail: dr.kamleshchaudhari@gmail.com

(C) 2014 Chaudhari KR et al. This is an open-access article distributed under the terms of the Creative Commons Attribution Non-Commercial License, which permits unrestricted non-commercial use, distribution, and reproduction in any medium, provided the original work is properly cited.

\begin{abstract}
Background: The aims of this study are 1) To study the accuracy of hysteroscopy in evaluation of abnormal uterine bleeding. 2) To correlate hysteroscopic findings with histopathology findings.

Methods: This is a prospective interventional study conducted in the dept. of obstetrics \& gynecology at K.J. Somaiya hospital in the period between January 2010 to December 2012. Women between 20-60 years of age of any parity who presented with complaints of Abnormal Uterine Bleeding (AUB) and who did not require any emergency management were enrolled in the study after excluding pregnancy, uterine/cervical infection/PID, cervical malignancy, H/o uterine perforation, patients on Oral Contraceptive Pills (OCPs), and presence of medical contraindication to any invasive procedure. A total of 98 women were included in the study. They were counselled and informed consent was taken. Patients were evaluated with detailed history, thorough examination and investigations. Hysteroscopy was done under total intravenous anaesthesia followed by endometrial biopsy. Hysteroscopic findings were then correlated with histopathology reports.

Results: The sensitivity, specificity, Positive Predictive Value (PPV), Negative Predictive Value (NPV) and accuracy of diagnostic hysteroscopy in the study was $98.3 \%, 80.5 \%, 89.7 \%, 96.7 \%$ and $91.8 \%$ respectively. For the diagnosis of endometrial hyperplasia these were $92 \%, 92 \%, 89 \%, 94 \%$, and $92 \%$ respectively. For polyp these figures were $94 \%, 96 \%, 87 \%, 98 \%, 95 \%$ respectively; for endometrial atrophy there were $66 \%, 95 \%, 60 \%, 98 \%$ and $94 \%$; for submucous fibroid $91 \%, 95 \%, 78 \%, 98 \%$, and 94\%; for malignancy $75 \%, 98 \%, 75 \%, 98 \%, 97 \%$ respectively.

Conclusions: With the above results it can be concluded that hysteroscopy is safe, sensitive and reliable diagnostic procedure. However endometrial biopsy improves the diagnostic accuracy of hysteroscopy.
\end{abstract}

Keywords: AUB, Hysteroscopy, Histopathology, Endometrial biopsy

\section{INTRODUCTION}

"A vigilant eye in the uterine cavity is better than
numerous blind curettages"- Lindmann.

AUB is a common clinical presentation; it amounts to $35 \%$ of office visits and $25 \%$ of gynecological surgeries and this incidence rises to $69 \%$ in peri or postmenopausal group $^{1}$ of women. It is difficult to diagnose the cause of AUB as it varies from DUB to endometrial cancer. The spectrums of conditions which may lead to AUB include endocrinological disorders on one side to malignancy on the other hand and hence it's vital to diagnose the cause of bleeding. Various methods to diagnose the cause of AUB include USG pelvis, sonohysterography, hysteroscopy and Dilatation and Curettage (D \& C). The primary goal of the clinical evaluation of AUB is to establish a specific diagnosis in the most efficient and least invasive manner. ${ }^{1}$ The most commonly used procedure traditionally is dilatation and curettage, which is a blind procedure which has to be done under general anaesthesia. Whereas hysteroscopy is a newer method done on OPD basis. Hysteroscopic evaluation permits the direct visualization and assessment of the endocervical and uterine cavities and hence proving a reliable method of diagnosing intrauterine abnormalities. ${ }^{2-4}$ As a matter of 
fact hysteroscopy is considered the gold standard for evaluating intrauterine abnormalities as its "Sees and decides" the cause of AUB.

\section{METHODS}

A prospective interventional study was conducted in the department of obstetrics and gynecology at the K.J. Somaiya medical college and research centre from January 2010 to December 2012.

A total of 98 patients with complaints of AUB in the age group of 20-60 years of any parity and those who didn't require emergency management were included in the study. Women who were pregnant or had history of cervicitis, vaginitis and endometritis, h/o current pelvic infection, H/o uterine perforation, patients on OC pills, patients with cervical malignancy and patients with medical contraindications to invasive procedure were excluded from this study. After taking detailed history, with thorough examination, investigations and informed consent patients were posted for diagnostic hysteroscopy.
Hysteroscopy was performed on all patients in the operation room with total intra venous anaesthesia (using fortwin, phenargan, midazolam, ketamine and propofol) by using rigid hysteroscope $(7 \mathrm{~mm})$ after dilating the cervix by serial dilatation with Hegar's dilators. Normal saline was used as distending medium.

Endometrial biopsy was performed using scissors/ biopsy forceps and the samples were sent for histological examination. Focal intrauterine lesions viz. polyps and myomas were removed in the same sitting and directed to histological examination.

All the patients were discharged 6 hours after the surgery from the hospital. There was no complication reported in any of these patients.

\section{RESULTS}

AUB is more common in multipara between 51-60 years of age (Table 1).

Table 1: Age and parity incidence.

\begin{tabular}{|llllll|}
\hline Age & Parity & & & No. of & Percentage \\
\hline 21-30 years & Nullipara & Multipara & Grand multipara & patients & (4) \\
\hline 31-40 years & 7 & 5 & 4 & 14 & 14.28 \\
\hline 41-50 years & 5 & 10 & 2 & 19 & 19.37 \\
\hline 51-60 years & 10 & 14 & 9 & 28 & 28.57 \\
\hline Total & 27 & 44 & 12 & 37 & 37.77 \\
\hline
\end{tabular}

Menorrhagia is the most common symptom seen in $39.79 \%$ of patients, followed by metrorrhagia seen in $19.37 \%$ (Table 2).

$30.61 \%$ of women had normal hysteroscopic findings (Table 3).

Endometrial hyperplasia is the most common abnormal hysteroscopic finding in patients with AUB (Table 3).
Table 2: Clinical presentation.

\begin{tabular}{|lll|}
\hline Symptom & $\begin{array}{l}\text { No. of } \\
\text { patients }\end{array}$ & Percentage \\
\hline Menorrhagia & 39 & 39.79 \\
\hline Metrorrhagia & 19 & 19.37 \\
\hline Menometrorrhagia & 15 & 15.30 \\
\hline Polymenorrhea & 15 & 15.30 \\
\hline Postmenopausal bleeding & 10 & 10.20 \\
\hline Total & 98 & \\
\hline
\end{tabular}

Table 3: Hysteroscopic findings.

\begin{tabular}{|c|c|c|c|c|c|c|c|c|c|}
\hline \multirow[b]{2}{*}{ Type of AUB } & \multicolumn{6}{|c|}{ Hysteroscopic findings } & \multirow{2}{*}{$\begin{array}{l}\text { No. of } \\
\text { abnormalities } \\
\text { detected }\end{array}$} & \multirow{2}{*}{$\begin{array}{l}\text { Total } \\
\text { no. of } \\
\text { patients }\end{array}$} & \multirow[b]{2}{*}{$\%$} \\
\hline & Normal & Hyperplasia & Polyp & Myoma & Atrophic & Malignancy & & & \\
\hline Menorrhagia & 05 & 18 & 10 & 06 & - & - & 34 & 39 & 39.79 \\
\hline Metrorrhagia & 08 & 03 & 04 & 04 & - & - & 11 & 19 & 19.37 \\
\hline Menometrorrhagia & 02 & 06 & 03 & 04 & - & - & 13 & 15 & 15.30 \\
\hline Polymenorrhea & 15 & - & - & - & - & - & - & 15 & 15.30 \\
\hline $\begin{array}{l}\text { Postmenopausal } \\
\text { bleeding }\end{array}$ & - & 02 & - & 02 & 02 & 04 & 10 & 10 & 10.20 \\
\hline Total & 30 & 29 & 17 & 16 & 02 & 04 & 68 & 98 & \\
\hline
\end{tabular}


Hysteroscopic findings and histopathology findings correlate well in cases of endometrial hyperplasia (29.49\% in hysteroscopy and $28.57 \%$ in histopathology) (Table 4).

Table 4: Comparison between hysteroscopic \& histopathological finding.

\begin{tabular}{|lll|}
\hline Findings & Hysteroscopic & Histopathology \\
\hline Normal & 30 & 36 \\
\hline $\begin{array}{l}\text { Endometrial } \\
\text { hyperplasia }\end{array}$ & 29 & 28 \\
\hline $\begin{array}{l}\text { Endometrial } \\
\text { polyp }\end{array}$ & 16 & 15 \\
\hline Fibroid & 14 & 12 \\
\hline $\begin{array}{l}\text { Endometrial } \\
\text { atrophy }\end{array}$ & 5 & 3 \\
\hline $\begin{array}{l}\text { Endometrial } \\
\text { malignancy }\end{array}$ & 4 & 4 \\
\hline Total & $30+68=98$ & $36+62=98$ \\
\hline
\end{tabular}

Out of $68(69.37 \%)$ abnormal hysteroscopic findings 61 $(62.24 \%)$ pts had abnormal histopathological reports (Table 5).
Table 5: Accuracy of hysteroscopy in diagnosis of intra uterine pathology.

\begin{tabular}{|lllll|} 
Hysteroscopy & $\begin{array}{l}\text { Histopath } \\
\text { abnormal }\end{array}$ & $\begin{array}{l}\text { Histopath } \\
\text { normal }\end{array}$ & Total & $\%$ \\
\hline Abnormal & 61 & 7 & 68 & 69.37 \\
\hline Normal & 1 & 29 & 30 & 30.62 \\
\hline Total & 62 & 36 & 98 & \\
\hline
\end{tabular}

Sensitivity of hysteroscopy is $98.3 \%$ and negative predictive value is $96.7 \%$ for diagnosis of intra uterine pathologies (Table 6).

Table 6: Different statistical values of hysteroscopy in diagnosis of intra-uterine pathologies.

\begin{tabular}{|ll|}
\hline Parameters & Percentage \\
\hline Sensitivity & $98.3 \%$ \\
\hline Specificity & $80.5 \%$ \\
\hline Positive predictive value & $89.7 \%$ \\
\hline Negative predictive value & $96.7 \%$ \\
\hline Accuracy of hysteroscopy & $91.8 \%$ \\
\hline
\end{tabular}

Table 7: Different statistical values of hysteroscopy in diagnosis of intra-uterine pathologies.

\begin{tabular}{|llllll|}
\hline & Sensitivity & Specificity & PPV & NPV & Accuracy \\
\hline $\begin{array}{l}\text { Endometrial } \\
\text { hyperplasia }\end{array}$ & 92 & 92 & 89 & 94 & 92 \\
\hline Polyp & 94 & 96 & 87 & 98 & 95 \\
\hline Myoma & 91 & 95 & 78 & 98 & 94 \\
\hline Atrophy & 66 & 95 & 60 & 98 & 94 \\
\hline Malignancy & 75 & 98 & 75 & 98 & 97 \\
\hline
\end{tabular}

\section{Hysteroscopic view of endometrial pathologies}

Figure 1-4 shows hysteroscopic view of endometrial pathologies.

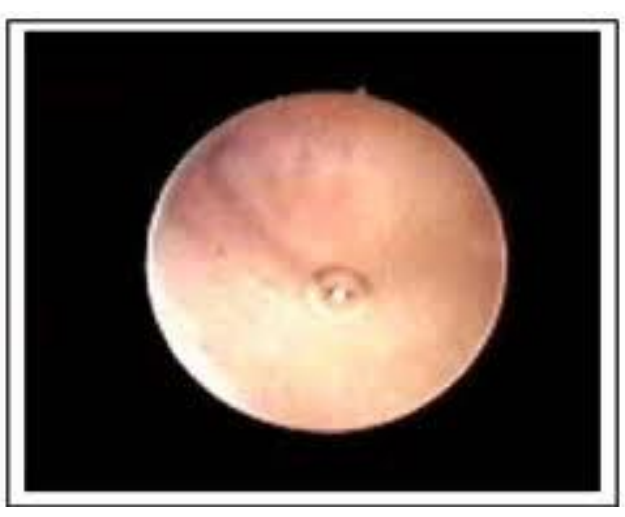

Figure 1: Simple hyperplasia without atypia.

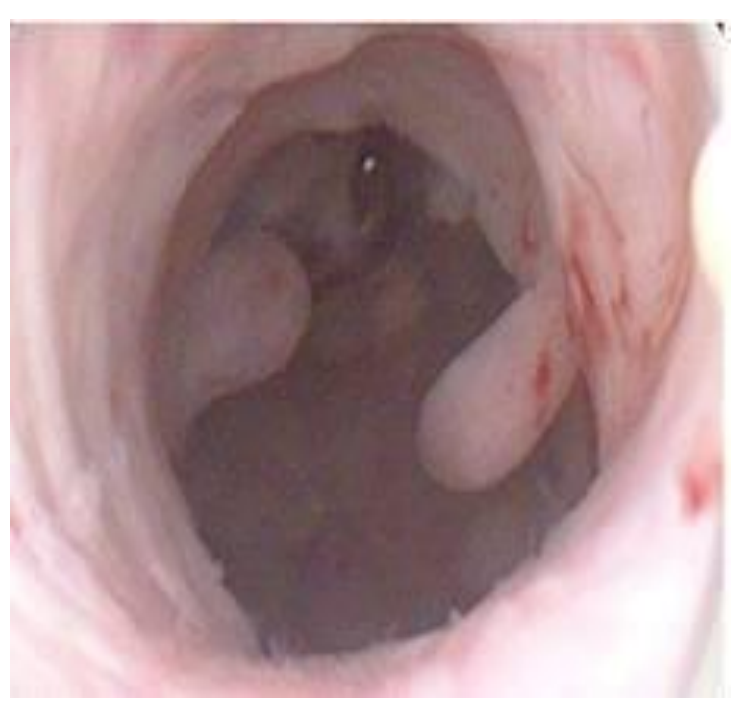

Figure 2: Submucous polyp. 


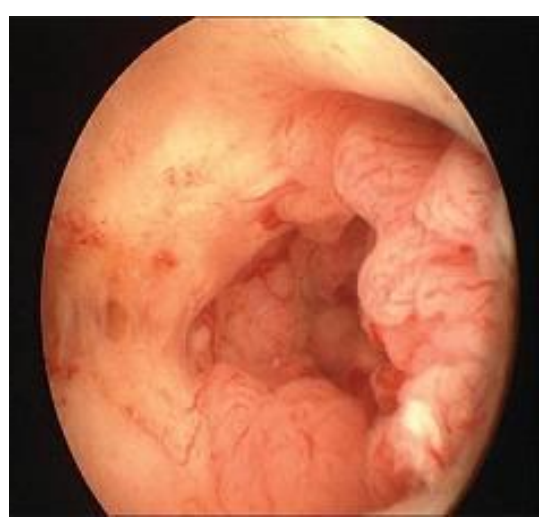

Figure 3: Ca endometrium.

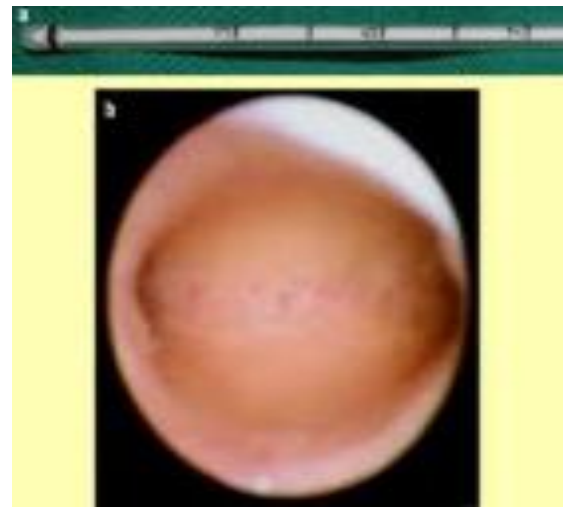

Figure 4: Atrophic endometrium.

\section{DISCUSSION}

AUB is an important and common problem encountered in gynaecological practice. Endometrial and uterine abnormalities such as leiomyoma, polyps and hyperplasia are more common than previously thought. With the aim of solving the problem, a precise diagnostics is required. Diagnostic curettage has been the method of choice to diagnose endometrial abnormalities ${ }^{2}$ for many years but hysteroscopy combined with histologic examination subsequently became the "gold standard" for such evaluation. $^{5}$

Hysteroscopy is a superior method that has high sensitivity and specificity in diagnosing the cause of AUB due to the fact that the uterine cavity and intrauterine pathology are directly visualized.
In this study 98 cases with AUB were included. It was observed that most of the patients were in the age group of 51-60 years with an average age of 44.2 years. This is consistent with findings in Trajkovic's study ${ }^{6}$ and Paulo Vercillini et al., Luigi Mangiuzulli University, Italy in which mean age of patients with AUB was 41.5+7.8 years.

The most common indication of hysteroscopy in the study was menorrhagia which was present in 39 (38.22\%) patients and least common indication was postmenopausal bleeding that was observed in $10(9.8 \%)$ patients. The most common cause of AUB in this study was endometrial hyperplasia $(27.44 \%)$ followed by endometrial polyp (14.7\%). These results were similar in the study conducted by Aisha Razzaq et al. ${ }^{3}$ in which $39 \%$ women presented with menorrhagia and $7.5 \%$ had postmenopausal bleeding.

In our study sensitivity, specificity, positive predictive value, negative predictive value and accuracy for hysteroscopy were $98.3 \%, 80.5 \%, 89.7 \%, 96.7 \%$ and $91.8 \%$ respectively. Following is the table comparing these values for hysteroscopy in AUB in other studies.

Table 8: A comparison of various parameters for detection of endometrial polyp in various studies.

\begin{tabular}{|llll|} 
Parameters & $\begin{array}{l}\text { A. Ravnaq } \\
\text { et al. }\end{array}$ & $\begin{array}{l}\text { Allamah } \\
\text { et al. }\end{array}$ & $\begin{array}{l}\text { Our } \\
\text { study }\end{array}$ \\
\hline Sensitivity & $93.3 \%$ & $93 \%$ & $94 \%$ \\
\hline Specificity & $98.5 \%$ & $100 \%$ & $96 \%$ \\
\hline Positive predictive value & $93.3 \%$ & $100 \%$ & $87 \%$ \\
\hline Negative predictive value & $98.5 \%$ & $95.4 \%$ & $98 \%$ \\
\hline Accuracy & $97.5 \%$ & - & $95 \%$ \\
\hline
\end{tabular}

Table 9: A comparison of various parameters for detection of endometrial hyperplasia in various studies.

\begin{tabular}{|llll|}
\hline Parameters & $\begin{array}{l}\text { A. Rayzaq } \\
\text { et al. }\end{array}$ & $\begin{array}{l}\text { Allamah } \\
\text { et al. }\end{array}$ & $\begin{array}{l}\text { Our } \\
\text { study }\end{array}$ \\
\hline Sensitivity & $75 \%$ & $75 \%$ & $92 \%$ \\
\hline Specificity & $96.9 \%$ & $89.7 \%$ & $92 \%$ \\
\hline Positive predictive value & $85.7 \%$ & $82.5 \%$ & $89 \%$ \\
\hline Negative predictive value & $93.5 \%$ & $93.3 \%$ & $94 \%$ \\
\hline Accuracy & $92.5 \%$ & - & $92 \%$ \\
\hline
\end{tabular}

Table 10: Comparison of various parameters in diagnosing intra-uterine pathologies by hysteroscopy.

\begin{tabular}{|lllllll|}
\hline Parameters & $\begin{array}{l}\text { Allamah } \\
\text { et al. }\end{array}$ & $\begin{array}{l}\text { Barati } \\
\text { et al. }\end{array}$ & $\begin{array}{l}\text { A. Razhaq } \\
\text { et al. }\end{array}$ & $\begin{array}{l}\text { Jakab } \\
\text { et al. }\end{array}$ & $\begin{array}{l}\text { Paschopaulos } \\
\text { et al. }\end{array}$ & $\begin{array}{l}\text { Our } \\
\text { study }\end{array}$ \\
\hline Sensitivity & $100 \%$ & $97.8 \%$ & $97.95 \%$ & $97 \%$ & $92 \%$ & $98.3 \%$ \\
\hline Specificity & $80.5 \%$ & $99 \%$ & $90.6 \%$ & & $95 \%$ & $80.5 \%$ \\
\hline Positive predictive value & $88.9 \%$ & $94 \%$ & $94 \%$ & - & - & $89.7 \%$ \\
\hline Negative predictive value & $100 \%$ & $99 \%$ & $96.7 \%$ & - & - & $96.7 \%$ \\
\hline Accuracy & - & - & - & - & - & $91.8 \%$ \\
\hline
\end{tabular}


Hysteroscopy is safe, highly sensitive diagnostic procedure. It ensures speed and safety of diagnosis \& treatment. However endometrial biopsy improves the diagnostic accuracy of hysteroscopy.

\section{ACKNOWLEDGEMENTS}

We would like to thank Dr. Geeta Niyogi, Dean of K.J. Somaiya Medical College \& Research Centre, who has allowed us to conduct this study.

\section{Funding: No funding sources}

Conflict of interest: None declared

Ethical approval: The study was approved by the institutional ethics committee

\section{REFERENCES}

1. Luigi Man, Paulo Vercellini. Role of TVS and outpatient diagnostic hysteroscopy in evaluation of AUB. Clinics of Obstetrics and Gynecology, 2014. Available at: http://endometriosis.org/.

2. Grimes DA. Diagnostic dilatation and curettage: a reappraisal. Am J Obstet Gynecol. 1982;142:1-6.
3. Aisha Razzaq, S. Shankar-ud-Din, N. Soomro. Role of diagnostic hysteroscopy in case of abnormal uterine bleeding. Pak J Surg. 2011;27(4):309-15.

4. Allamah T, Mohammadizadeh F. diagnostic value of hysteroscopy in abnormal uterine bleeding compared to pathology reports. Iranian $\mathrm{J}$ Reprod Med. 2007;5:61-4.

5. Clark TJ, Mann CH, Shah N, Song F, Khan KS, Gupta JK. Accuracy of outpatient endometrial biopsy in the diagnosis of endometrial cancer: a systematic quantitative review. $\mathrm{Br} \mathbf{J}$ Obstet Gynecol. 2002;109:313-21.

6. Sonja Pop Trajkovic. Role of hysteroscopy in evaluation of patients with AUB. Clinic for gynecology and obstetrics, clinic centre Serbia. Sci J Faculty Med. 2011;28(3):177-81.

7. Barati Mojgan, Masihi S, Moramezi F, Salemi S. Office hysteroscopy in patients with abnormal uterine bleeding and normal transvaginalsonography. Int J Fertil Steril. 2008;4:175-8.

DOI: $10.5455 / 2320-1770 . i j \operatorname{cog} 20140958$

Cite this article as: Chaudhari KR, Sathe P. Role of diagnostic hysteroscopy in evaluation of abnormal uterine bleeding and its histopathological correlation. Int J Reprod Contracept Obstet Gynecol 2014;3:666-70. 